\title{
Settlement and distribution of Age-0 juvenile cod, Gadus morhua and G. ogac, following a large-scale habitat manipulation
}

\author{
B. J. Laurel ${ }^{1, *}$, R. S. Gregory ${ }^{2}$, J. A. Brown ${ }^{1}$ \\ ${ }^{1}$ Ocean Sciences Centre, Memorial University of Newfoundland, St. John's, Newfoundland, A1C 5S7, Canada \\ ${ }^{2}$ Department of Fisheries and Oceans, Science Branch, PO Box 5667, St. John's, Newfoundland, A1C 5X1, Canada
}

\begin{abstract}
In Bonavista Bay, Newfoundland, we monitored patterns of settlement and distribution of 2 species of gadids, Atlantic cod Gadus morhua and Greenland cod G. ogac, following a largescale alteration of nearshore eelgrass Zostera marina habitat. Comparisons between control and experimental sites, based on bi-weekly sampling from 1995 to 2001, indicated a significant increase in cod abundance at sites enhanced with simulated eelgrass and a corresponding decrease in cod numbers at sites where eelgrass had been removed. These data supported predictions, demonstrating that: (1) there was a sufficient supply of juvenile cod within the areas that have historically been unoccupied (i.e. sand) and (2) both species preferred to settle in complex habitats. However, G. ogac responded significantly to the removal of eelgrass in more comparisons than G. morhua (70 and $37 \%$ respectively), suggesting that $G$. ogac has a higher affinity for complex vegetative habitats than G. morhua at the scale of manipulation (ca. $800 \mathrm{~m}^{2}$ ). Furthermore, despite an overall preference for eelgrass habitat, high within-site catch variation of post-settled juvenile cod indicated that both species were not restricted to a seine site. Such variation was occurring well after the settlement period, suggesting that juvenile cod were moving and occasionally aggregating (i.e. shoaling) throughout the study period. Our results support previously described associations between juvenile cod and eelgrass, but contradict other published accounts of high site-attachment and restricted movement in G. morhua following settlement.
\end{abstract}

KEY WORDS: Eelgrass $\cdot$ Habitat selection · Atlantic cod $\cdot$ Greenland $\operatorname{cod} \cdot$ Habitat enhancement · BACI design Resale or republication not permitted without written consent of the publisher

\section{INTRODUCTION}

The identification of critical nursery habitat has become an important task for the management of commercially important marine fish species (e.g. Schmitten 1996). Although habitat use is known to be species-specific, many studies have demonstrated that nearshore abundance and diversity of juvenile fish is often higher in eelgrass (Zostera spp.) habitats relative to simple, unvegetated mineral substrates (Bell \& Pollard 1989, Edgar \& Shaw 1995a,b, Mattila et al. 1999). Eelgrass has been shown to provide refuge for juvenile fish species in laboratory observations (Gotceitas et al. 1995, 1997), tethering studies (Linehan et al. 2001, Laurel et al. 2003) and predator-exclusion experiments
(Hindell et al. 2000). High food levels (Connolly 1994 Parker et al. 2001), reduced physical exposure (Bell \& Pollard 1989) and increased water quality (Orth et al. 1984) are other possible benefits of nearshore eelgrass habitat to juvenile fish.

Regardless of the survival and growth benefits associated with eelgrass, habitat quality may not always predict fish distribution. Competitive interactions may prevent pelagic juveniles from initially settling in areas of preferred habitat (Sweatman 1985). Post-settlement processes (e.g. emigration or mortality) may later reshape distributions of juvenile fish settling in poorquality habitat (e.g. Tupper \& Boutlier 1995a). Fishhabitat relationships can also break down, due to large-scale processes such as differential larval supply 
(Bell \& Westoby 1986, Caselle \& Warner 1996, Jenkins et al. 1997a, 1998). Jenkins et al. (1996) found that juvenile whiting abundance decreased in eelgrass habitats further from the spawning ground, a result attributed to a diminishing supply of pre-settling juveniles. Differential larval supply may also affect overall community structure in eelgrass, including the abundance and diversity of juvenile fish and their prey species (Bell et al. 1988). Although these patterns may disappear through eventual movement to a habitat of higher quality (Sogard 1989), initial settlement patterns have prolonged effects on the distribution of fish if post-settlement movement is limited (Bell \& Westoby 1986, Tupper \& Boutlier 1995a). Therefore, evaluating critical nursery habitat for juvenile fish has to be considered from multiple spatial and temporal scales.

Generally, habitat studies for marine fish have been conducted as either laboratory experiments, smallscale field manipulations or large-scale field observations. Laboratory and small-scale field experiments typically investigate how the behaviour of an organism influences habitat use, i.e. habitat selection. In the laboratory, predators or food may be introduced to determine how fish choose habitats when faced with tradeoffs between predator risk and opportunities for faster growth (e.g. Schmitt \& Holbrook 1985, Holbrook \& Schmitt 1988). Such studies are useful in isolating small-scale processes, but may not always reflect patterns of habitat use in the field. Alternatively, smallscale field experiments may be insufficient in area to convey the fitness benefits (e.g. predator refuge) necessary for habitat selection to occur (Laurel et al. 2003). Instead, small habitat manipulations may be best suited to smaller, more sedentary marine organisms such as shellfish (e.g. Irlandi 1997) and certain species of reef fish (e.g. Levin 1991). It is perhaps for these reasons that in situ habitat studies of marine fish are most commonly investigated through large-scale field observations. Although these studies examine fish distribution in the context of large-scale phenomena (e.g. physical processes, pelagic larval supply, predator distribution), they lack an experimental framework in which to measure the mechanisms contributing to the observed patterns of distribution. Thus, it has been difficult to resolve the contribution of small (e.g. behavioural) and large (e.g. oceanographic) scale processes of habitat use in many marine fish species.

One solution is to conduct controlled in situ experiments with habitat on large scales. Aquatic field experiments are not novel, but seagrass manipulations are typically restricted to less than $4 \mathrm{~m}^{2}$ (Sogard 1989, Irlandi 1997, Horinouchi \& Sano 1999, Lee et al. 2001, Jenkins et al. 2002). Larger-scale habitat manipulations are ideal when investigating fish-habitat relationships, but spatial replication of these studies is logistically difficult. Similarly, removing large areas of potentially critical fish habitat may have long-term detrimental consequences to the species being investigated. However, recent statistical tools using randomized time replicates in conjunction with historical data have reduced statistical requirements for spatial replication (randomized intervention analysis, RIA; Carpenter et al. 1989). With such tools, it is logistically possible to carry out large-scale habitat-manipulation experiments.

We conducted a large-scale habitat-manipulation experiment to determine the effect of eelgrass (Zostera marina) on the distribution of juveniles of $2 \operatorname{cod}$ species, Atlantic cod Gadus morhua and Greenland cod G. ogac. Age-0 juvenile cod associate with a number of highly structured demersal habitats (i.e. reefs, cobble, eelgrass; Lough et al. 1989, Tupper \& Boutilier 1995a,b). However, juvenile cod distribution in the waters off Newfoundland is almost exclusively restricted to eelgrass habitat in nearshore areas (Gotceitas et al. 1997), where abundance is highly variable among beds of this plant (Grant \& Brown 1998a). In this study, we added and removed large sections of eelgrass to investigate sources of variability of habitat use in juvenile cod. Specifically, we addressed the following questions: (1) Is eelgrass a preferred habitat for juvenile cod? (2) Does the association of juvenile cod with habitat occur during or after settlement? (3) Are patterns of habitat use similar between 2 congeneric species?

\section{MATERIALS AND METHODS}

Study species. Juvenile Age-0 Gadus morhua and G. ogac are found throughout Newfoundland nearshore coastal waters from August to late December (Methven \& Bajdik 1994, Gotceitas et al. 1997, Grant \& Brown 1998a). Both species are similar in appearance at early life stages $(<100 \mathrm{~mm}$ SL) but can be distinguished in the field using lateral line characteristics (Methven \& McGowan 1998) and pigment patterns (B. J. Laurel \& R. S. Gregory pers. obs.).

The reproductive life histories differ between the 2 species. Gadus ogac spawn early (February to March), have demersal eggs and spawn in the nearshore (Scott \& Scott 1988). G. ogac are considered demersal and non-schooling residents of the nearshore throughout their life (Mikhail \& Welch 1989). In contrast, G. morhua spawn later (March to April), have pelagic eggs and spawn in deep water both offshore (Templeman 1979) and inshore (Smedbol et al. 1998). Eggs, larvae and pre-settling juveniles of G. morhua are transported to the nearshore, where they eventually settle from the pelagial. The 2 species co-occur as demersal juveniles. 


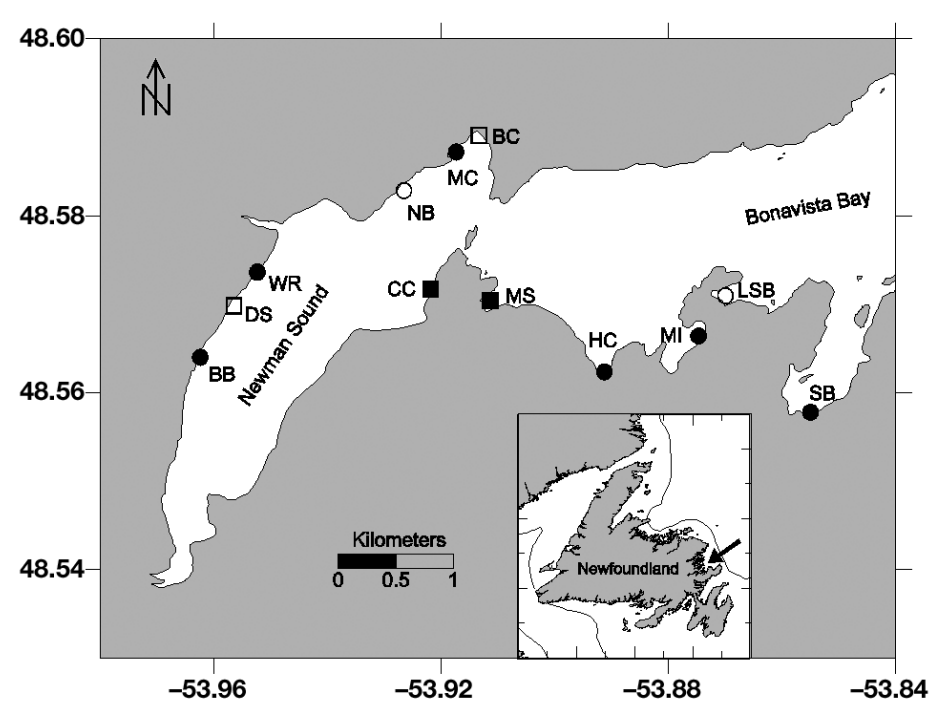

Fig. 1. Study area in Newman Sound, Bonavista Bay, Newfoundland, showing the locations of experimental and reference seine locations. CC: Canning's Cove; MS: Mount Stamford; NB: Newbridge; LSB: Little South Broad Cove; BC: Buckley's Cove; DS: Dockside; BB: Big Brook; HC: Hefferen's Cove; MC: Minchin's Cove; MI: Mistaken Cove; SB: South Broad Cove; WR: White Rock. (๑) Eelgrass site, (ロ) artificial eelgrass site, (O) unvegetated site, $(\square)$ removal site

Study area. Newman Sound is a moderately sized (ca. $45 \mathrm{~km}^{2}$ ) protected fjord of Bonavista Bay, Newfoundland located adjacent to Terra Nova National Park (TNNP; Fig. 1). Tidal amplitude in the sound is relatively low (1 to $1.5 \mathrm{~m}$ ) and temperatures vary seasonally from $18.0^{\circ} \mathrm{C}$ in August to $-1.5^{\circ} \mathrm{C}$ in late December. Eelgrass is the dominant vegetative nearshore habitat, found extensively along the western and southern shores of the sound. Unvegetated mineral substrates are found throughout the sound, comprising the majority of habitat along the northern shore.

Experimental design. We selected 12 sites - 8 'eelgrass' (eelgrass + mud/silt) and 4 'non-eelgrass' (mud/sand) - along southern and eastern sections of Newman Sound (Fig. 1). Eelgrass was removed from 2 eelgrass sites (BC and DS) and artificial eelgrass was added to 2 non-eelgrass sites (CC and MS). Remaining unmanipulated eelgrass and non-eelgrass sites (6 and 2 respectively) were used as controls.

Habitat removal was accomplished by scuba divers in mid-July 1999, approximately $2 \mathrm{wk}$ prior to juvenile cod settlement. Divers marked each site with highly visible transect lines at $1 \mathrm{~m}$ intervals over a $500 \mathrm{~m}^{2}$ area. Eelgrass was harvested between lines by breaking stems away from the rhizome at the base of the substrate. The process was repeated until the entire eelgrass canopy was removed in the $500 \mathrm{~m}^{2}$ area at each site.
Artificial eelgrass was constructed for 2 sites by attaching green, plastic ribbon (width: $0.8 \mathrm{~cm}$; height: $75.0 \mathrm{~cm}$ ) to galvanized wire fencing. Ribbon densities fell within the range of eelgrass naturally occurring in Newman Sound, i.e. 600 blades $\mathrm{m}^{2}$. A total of $80 \mathrm{~m}^{2}$ of artificial eelgrass was created for each enhancement site, and this was divided into a series of smaller patches to mimic the fragmented characteristics of natural eelgrass. Two replicates of 5 patch sizes $(0.3$, $1.1,5.5,11,22 \mathrm{~m}^{2}$ ) were deployed at both $\mathrm{CC}$ and $\mathrm{MS}$, covering a total area of $275 \mathrm{~m}^{2}$ at each site (Fig. 2). Patches were spaced 2 to $3 \mathrm{~m}$ apart and secured to the benthos with $25 \mathrm{~cm}$ rebar spikes by divers. Fish were allowed to settle on artificial eelgrass patches for a period of $2 \mathrm{wk}$ before the sampling protocol was initiated. Patches were removed in November 1999 and redeployed in July of 2000 to prevent potential icescour damage.

Juvenile cod sampling. A $25 \mathrm{~m}$ demersal seine net with $19 \mathrm{~mm}$ stretched mesh size was used to collect fish over all sampling sites. The net was deployed from a small boat $50 \mathrm{~m}$ from shore and retrieved to shore by 2 individuals standing $16 \mathrm{~m}$ apart. The seine sampled $880 \mathrm{~m}^{2}$ of habitat from the substrate to $2 \mathrm{~m}$ into the water column and has been shown to have a capture efficiency of $95 \%$ (Gotceitas et al. 1997). We made a series of underwater observations in 1999, using scuba, over all substrates, and confirmed that entire sites were sampled and that fish in the path of the seine did not escape capture. Fish caught in the seine were transferred to holding containers with seawater, identified, measured to the nearest $\mathrm{mm}$ (standard length, SL) and then returned alive to the original site of capture. Juveniles were considered 'pre-settled' if SL $<60 \mathrm{~mm}$ and 'post-settled' if SL $\geq 60$ mm (Templeman 1966, Fahay 1983, Methven \& Bajdik 1994, Tupper \& Boutlier 1995a,b). We use the term 'pre-settled' to describe a juvenile cod early in the transition from pelagic to demersal life (synonymous terms include 'recently settled'

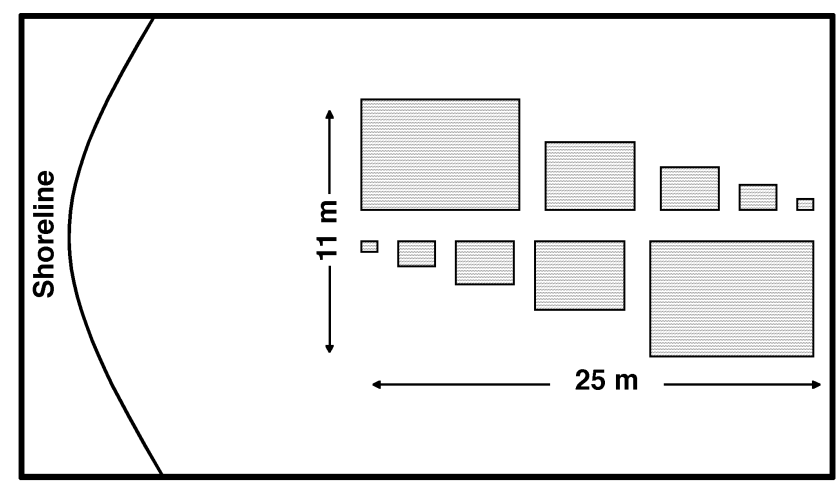

Fig. 2. Experimental layout of artificial eelgrass patches relative to shore at MS and CC 
[Grant \& Brown 1998a,b] and 'newly settled' [Tupper \& Boutilier 1995a]). Our choice of terminology was intentional, since juvenile cod do not have a distinct settlement point and individuals larger than $60 \mathrm{~mm}$ SL may continue to forage on semi-pelagic prey such as calanoid copepods (Grant \& Brown 1998a, Lomond et al. 1998). However, the seine we used samples the lowermost $2 \mathrm{~m}$ of the water column (i.e. near the bottom), and captures only those juvenile cod which are likely associated with the demersal habitat. All sites were sampled within $2 \mathrm{~h}$ of low tide during daylight hours on a bi-weekly basis in both pre- manipulated years
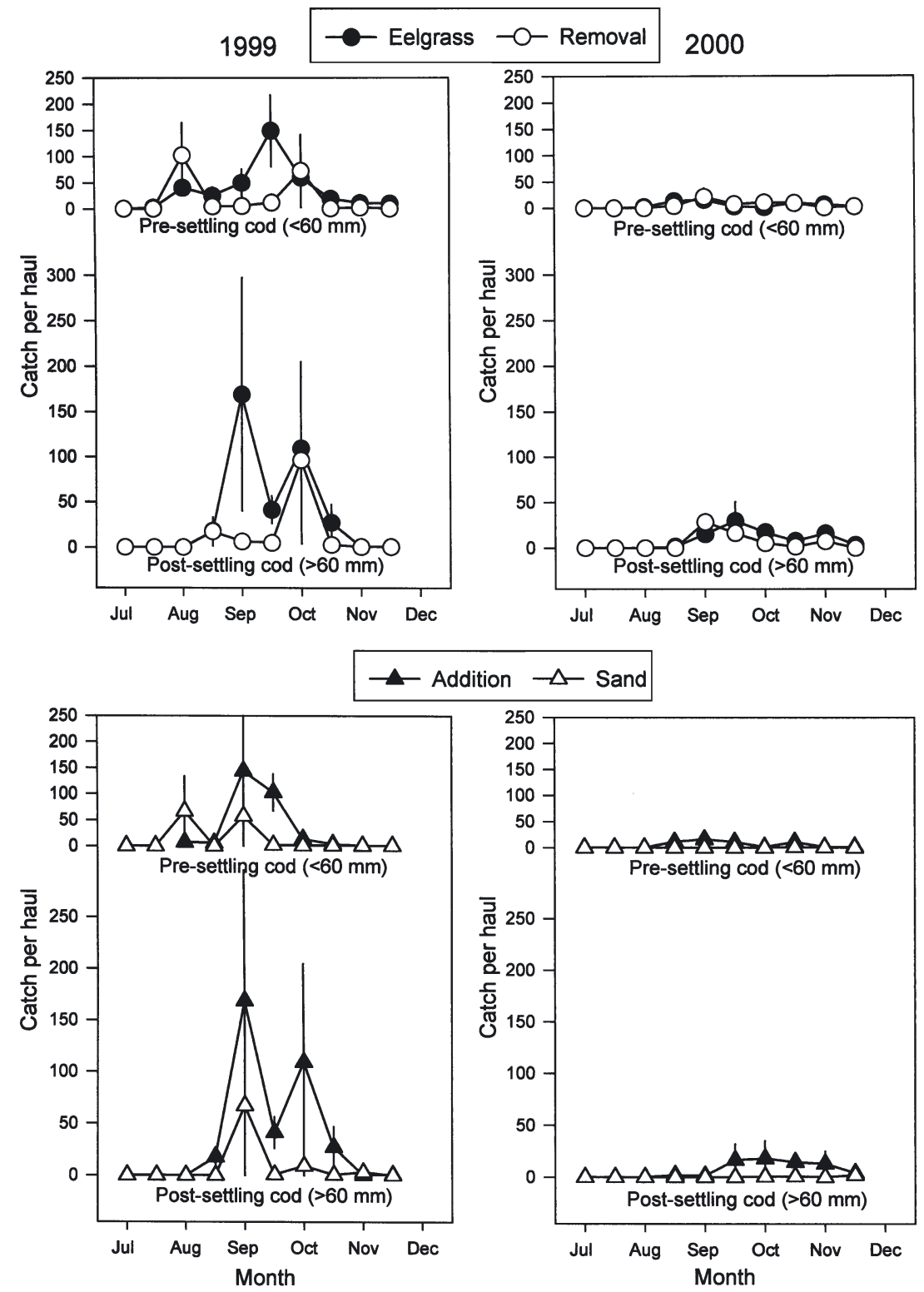

Addition $\triangle-$ Sand

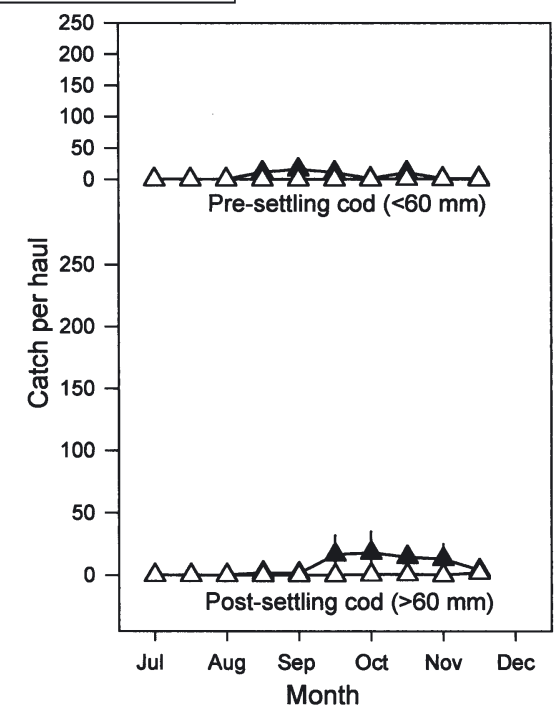

Fig. 3. Gadus morhua. Interannual pre- and post-settlement distribution of Age-0 juveniles in experimental and reference sites. Values are means of seine hauls at replicate sites $(n=2-6) \pm \mathrm{SE}$
(1995, 1996 and 1998) and post-manipulated years (1999 and 2000). Removal sites were additionally sampled in 2001 to measure long-term effects of habitat removal on juvenile cod distribution.

Additional density estimates of juvenile cod were made visually using the snorkeling methods described by Laurel et al. (2003). This was accomplished by deploying two $15 \mathrm{~m}$ transect lines perpendicular to the shore at 2 sites of each treatment (addition, removal, eelgrass, and sand; $2 \times 4=8$ total sites, 2 transects per site). At artificial eelgrass sites, snorkelers surveyed only fish directly over or within $0.5 \mathrm{~m}$ of artificial habitat patches. Juvenile cod surveys in other treatment habitats (i.e. removal, eelgrass and sand treatments) were designed to mimic the layout and area of artificial eelgrass at the addition sites (i.e. 10 patches, $80 \mathrm{~m}^{2}$ total). This was accomplished by marking the length and spacing of artificial eelgrass patches on each transect line with highly visible tape. The survey width along the transect lines was determined using a delineated plastic pole. Using both the transect line and poles, snorkelers were capable of surveying juvenile cod at the same dimensions as addition sites along each transect line, i.e. 0.3, 1.1, 5.5, 11.0 and $22 \mathrm{~m}^{2}$. At all sites, large patches (11 and $22 \mathrm{~m}^{2}$ ) exceeded the viewing capability of a single snorkeler, so these patches were assessed by 2 snorkelers swimming in parallel. Location and abundance of Age- 0 cod were recorded on underwater slates. Surveys were only performed when water clarity exceeded the maximum area censused by a single snorkeler, i.e. $2.8 \mathrm{~m}$. However, we were often unable to distinguish between the smallest Gadus ogac and G. morhua underwater, even when within $1 \mathrm{~m}$. Therefore, we pooled our juvenile cod observations during snorkel surveys as Gadus spp. We surveyed the sites approximately weekly $(n=9)$ between 10 August and12 October 2000 (a total of 144 transect surveys).

Data analysis. Catch data were analyzed using RIA to test whether a significant change in fish density occurred after the habitat manipulation. A full description of RIA and its utility for detecting treatment effects has been reviewed by Carpenter et al. (1989). RIA is based on a before-aftercontrol-impact (BACI) design model in which experimental and control sites are 
compared against each other both before and after any experimental intervention. Removal sites $(n=2)$ were compared against natural eelgrass sites $(n=6)$; artificial eelgrass sites $(n=2)$ were compared against naturally unvegetated sites $(n=2)$. RIA tests were performed on data from individual and combined years in all possible experiment-control site comparisons. However, combined years (1999 to 2001) were not included in the analysis of removal sites, because annual regrowth at each site effectively changed the treatment over time. Catch data were transformed $y=$ $\left.\log _{10}(x+1)\right]$ prior to analysis to control for interannual variation in cod abundance. Each RIA calculated differences between fish abundance at control and manipulated sites during each survey period. The mean of these differences both before $\left(\bar{E}_{\mathrm{PRE}}\right)$ and after the experimental manipulation $\left(\bar{E}_{\mathrm{POST}}\right)$ was used to generate the test statistic $\left[\bar{E}_{(\mathrm{PRE})}-\right.$ $\left.\bar{E}_{(\mathrm{POST})}\right]$. The test statistic was then compared against 5000 random permutations of $\left[\bar{E}_{(\mathrm{PRE})}-\bar{E}_{(\mathrm{POST})}\right]$ using the data of each experiment-control site comparison. The error distribution was self-derived from the randomization, and therefore data did not have to meet the assumptions of normality.

\section{RESULTS}

Juvenile Age-0 Gadus morhua settled in 2 pulses: the first pulse in late August, the second approximately 30 d later (Fig. 3). G. ogac settled in a single pulse at the beginning of August (Fig. 4). Interannual variation in abundance of G. morhua was high between 1999 and 2000 (Fig. 3), almost an order of magnitude higher in $1999(\mathrm{n}=6405)$ than in $2000(\mathrm{n}=$ 845). G. ogac abundance varied little between $1999(\mathrm{n}=8985)$ and $2000(\mathrm{n}=$ 6614), but was higher than G. morhua in all years.

The distribution of pre- and postsettled cod differed between habitat, species and year. Pre- and postsettled cod $(<60 \mathrm{~mm} \mathrm{SL})$ of both species were present in all habitats in 1999, but were not present at sand sites in 2000 (Figs. 3 \& 4). Differences in the abundance of post-settled Gadus morhua caught in natural eel- grass and removal sites were more apparent in the first year of the removal (1999) than in later years. However, post-settled G. ogac were seldom caught in the removal sites during both years.

Snorkelers observed juvenile cod settling within the artificial eelgrass in early August, approximately $2 \mathrm{wk}$ after patches were deployed. Gadus spp. were detected only in natural and artificial eelgrass sites at the time of settlement for both the first pulse (August 10 to 30 ) and second pulse (October 1 to 12; Fig. 5). Lower numbers of cod were observed in the removal sites, and these fish were often seen along the edge area of
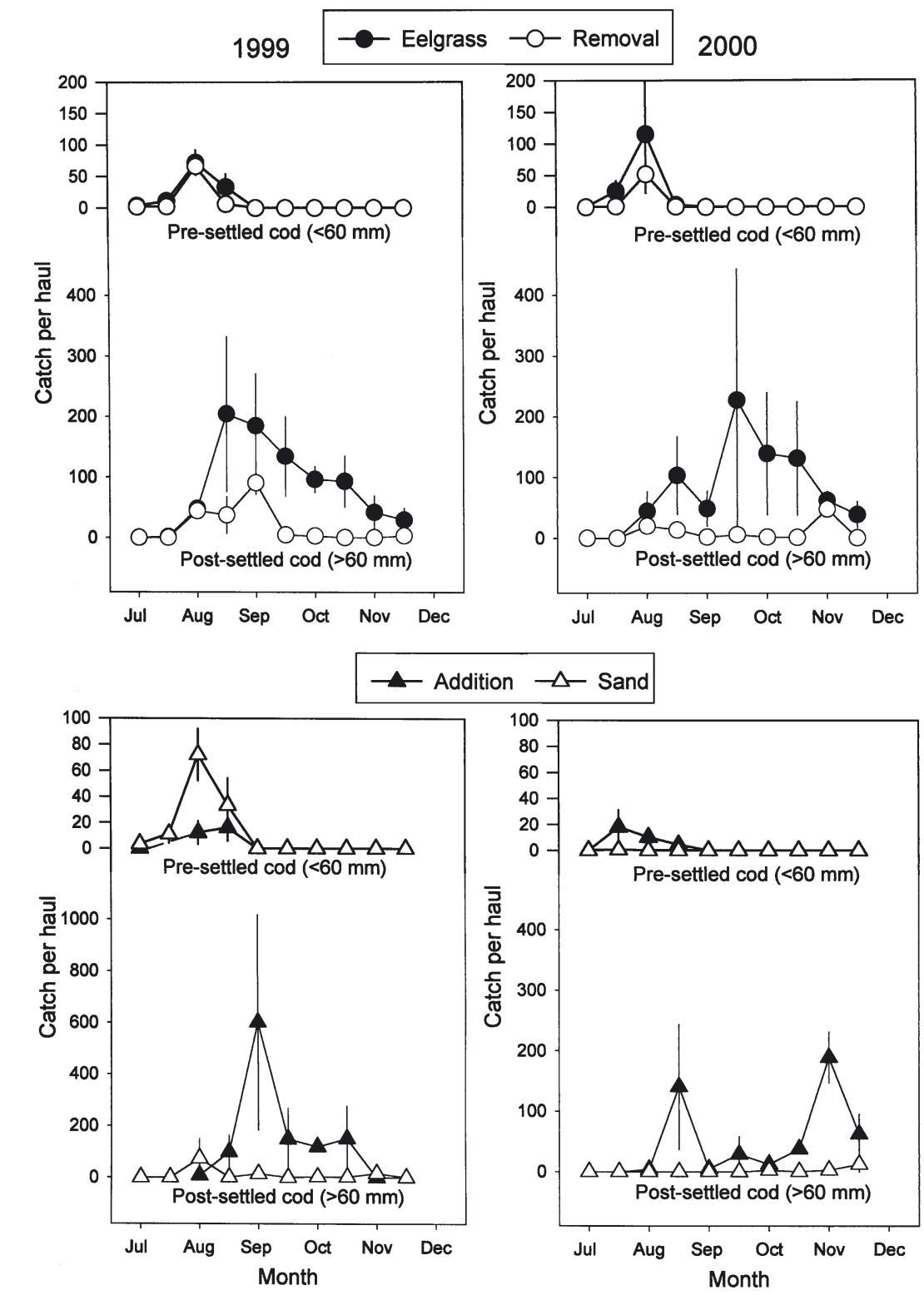

Fig. 4. Gadus ogac. Interannual pre- and post-settlement distribution of Age-0 juveniles in experimental and reference sites. Values are means of seine hauls at replicate sites $(n=2-6) \pm \mathrm{SE}$ 


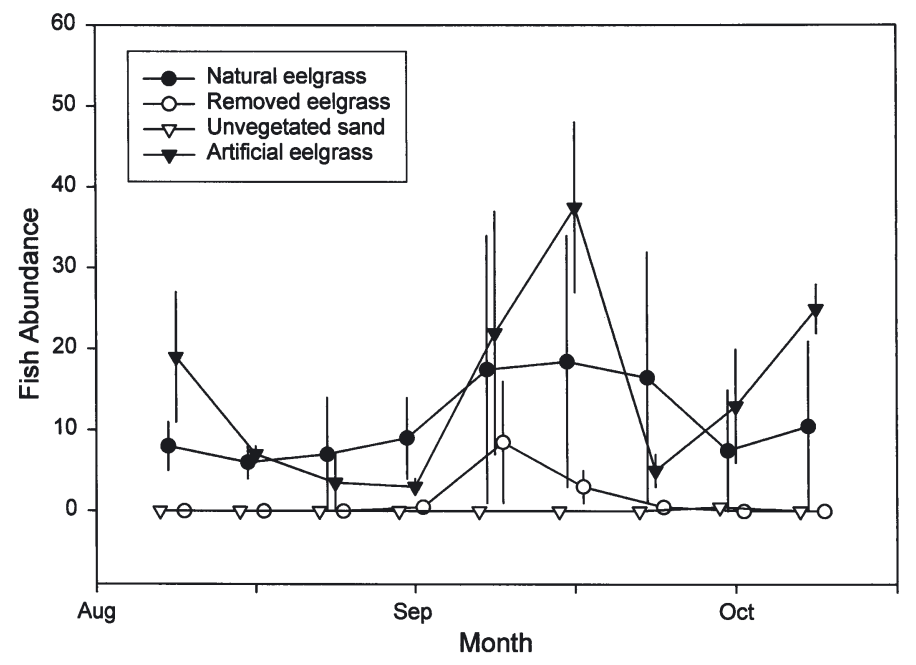

Fig. 5. Visual observations of Age-0 juvenile cod Gadus spp. abundance over a 9 wk period (August 12 to October 12) at eelgrass, removal, unvegetated sand and artificial eelgrass sites. Values are means of replicate transect lines $(n=4) \pm S E$. Points at each week are staggered $(0.1 \mathrm{wk})$ for visual purposes species showed signs of recovery towards the end of the experiment. Mean abundance of cod was lower in nearly all control site comparisons in all years following the removal of eelgrass (Table 2). In the first year of removal (1999), 50 and $75 \%$ of comparisons indicated a significant decline in abundance of G. morhua and G. ogac respectively (Table 2, Figs. 7 \& 8). In 2000, $16.7 \%$ of G. morhua and $50 \%$ of G. ogac comparisons were significantly lower than historic levels. However, in the final year (2001), with the exception of one $G$. morhua comparison, fish abundance generally recovered to historic levels (1995 to 1998).

\section{DISCUSSION}

Eelgrass benefits juvenile fish by reducing predator risk (Linehan et al. 2001, Laurel et al. 2003), increasing food availability (Connolly 1994), improving water quality and reducing physical exposure (Orth et al. 1984). However, juvenile fish may be distributed inde- the removal. Almost no cod were sighted over open sand areas (<0.1\% of all observations).

The RIA of catch data indicated a positive change in cod abundance in response to the artificial eelgrass, but the magnitude of the response differed between species and years. Differences were attributed to high catch variability at one unvegetated control site (LSB) rather than an absence of cod at the artificial eelgrass sites (Figs. 3 \& 6). In combined years (1999 and 2000), there was a significant increase in Gadus ogac abundance at artificial eelgrass sites in all comparisons. In contrast, increases in G. morhua at the artificial eelgrass sites were significant in comparisons with the unvegetated control site NB (Table 1, Fig. 6). However, the trends were similar between species in individually analyzed years. Seine catches of G. ogac and G. morhua were higher at artificial eelgrass sites relative to unvegetated control sites in $50 \%$ of comparisons in 1999 and $100 \%$ in 2000 (Table 1).

Gadus ogac and G. morhua also responded differently to eelgrass removal, although both

Fig. 6. Gadus morhua and Gadus ogac. Relative differences of juvenile abundance at artificial eelgrass sites (CC and MS) and unvegetated reference sites (NB and LSB) during pre- and post-manipulation years. Values represent annual mean bi-weekly seine catches $(\mathrm{n}=14-20) \pm$ SE. Points at each year are staggered $(0.05 \mathrm{yr})$ for visual purposes
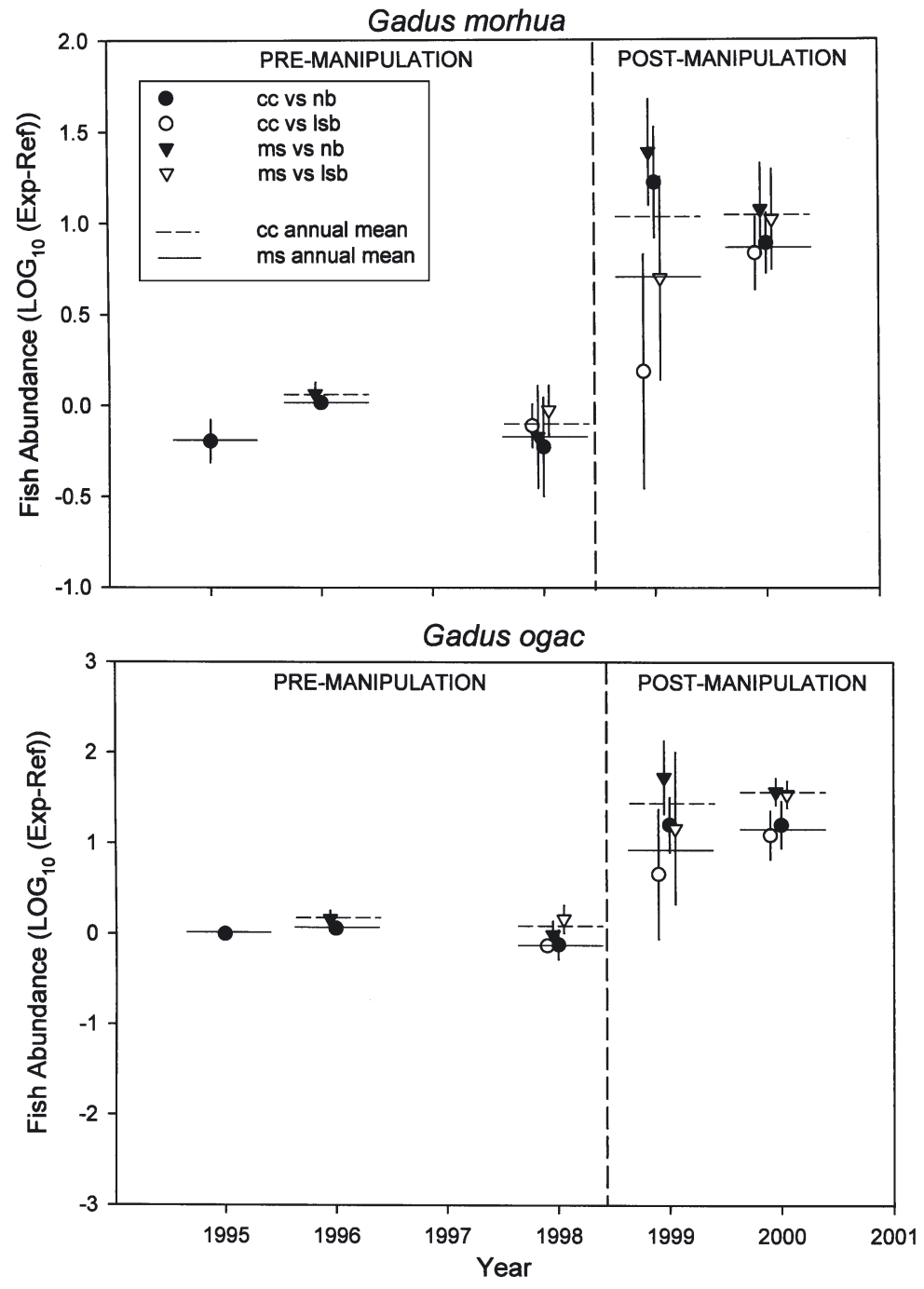
pendent of habitat quality. Differential planktonic supply (Bell \& Westoby 1986, Caselle \& Warner 1996, Jenkins et al. 1997a, 1998), competitive interactions (e.g. Sweatman 1985) or indiscriminate settlement patterns (Tupper \& Boutlier 1995a) are known to influence spatial distribution. Therefore, proposed mechanisms of habitat use in juvenile cod have been equivocal, despite frequent observations of associations between cod and eelgrass in the field (Morin et al. 1991, Gotceitas et al. 1997, Grant \& Brown 1998a). Our study experimentally demonstrates that differential habitatuse in Age- 0 juvenile cod is, in part, behaviourally mediated. Juvenile cod appeared to differentiate between habitats of varying quality and preferentially occupied eelgrass areas where growth and survival were potentially highest.

Habitat decision-making occurred at the time of settlement $(<60 \mathrm{~mm} \mathrm{SL})$, when fish were not fully demersal. Prior to the habitat manipulation, settling cod were restricted to areas with natural eelgrass. However, following the deployment of artificial eelgrass, pre-settling Gadus ogac and G. morhua were caught at sites historically unoccupied. These data suggest that planktonic supply over non-eelgrass areas was not limiting prior to the deployment of artificial eelgrass, but rather that cod were delaying settlement until preferential habitat was encountered. Although active habitat selection from the pelagial has been reported in other fish species (e.g. Marliave 1977, Sale 1984, Levin 1991), these data contradict other published accounts of settlement in cod. In a one year study, Tupper \& Boutilier (1995a) described an indiscriminate settlement pattern in G. morhua across habitats of varying complexity. In their study, differences in
Table 1. Probability values from randomized intervention analysis (RIA) of Gadus morhua and Gadus ogac from 2 artificial eelgrass sites (CC and $\mathrm{MS}$ ) and 2 unvegetated reference sites (NB and LSB). (+) indicates a positive effect from the enhancement $\left({ }^{*} \mathrm{p}<0.05,{ }^{* *} \mathrm{p}<0.01\right)$

\begin{tabular}{|llll|}
\hline Year & Site & NB & LSB \\
\hline G. morhua & & & \\
$1999-2000$ & $\mathrm{CC}$ & $(+) 0.001^{* *}$ & $(+) 0.251$ \\
& $\mathrm{MS}$ & $(+) 0.001^{* *}$ & $(+) 0.063$ \\
1999 only & $\mathrm{CC}$ & $(+) 0.001^{* *}$ & $(+) 0.670$ \\
& $\mathrm{MS}$ & $(+) 0.001^{* *}$ & $(+) 0.190$ \\
2000 only & $\mathrm{CC}$ & $(+) 0.001^{* *}$ & $(+) 0.002^{* *}$ \\
& $\mathrm{MS}$ & $(+) 0.001^{* *}$ & $(+) 0.006^{* *}$ \\
G. ogac & & & \\
$1999-2000$ & $\mathrm{CC}$ & $(+) 0.001^{* *}$ & $(+) 0.041^{*}$ \\
& $\mathrm{MS}$ & $(+) 0.001^{* *}$ & $(+) 0.034^{*}$ \\
1999 only & $\mathrm{CC}$ & $(+) 0.002^{* *}$ & $(+) 0.276$ \\
2000 only & $\mathrm{MS}$ & $(+) 0.001^{* *}$ & $(+) 0.200$ \\
& $\mathrm{CC}$ & $(+) 0.001^{* *}$ & $(+) 0.001^{* *}$ \\
& $\mathrm{MS}$ & $(+) 0.001^{* *}$ & $(+) 0.001^{* *}$ \\
\hline
\end{tabular}

abundance of cod between habitats occurred after settlement. They suggested that this was a result of differential predator-induced mortality rather than habitat selection. Our observations did not suggest indiscriminate settlement in 5 of the 6 years of our catch data $(1995,1996,1998,2000$ or 2001). However, in the year of highest overall juvenile cod abundance (1999), presettled cod were caught at all sites, supporting the observations of Tupper \& Boutlier (1995a). Their study also indicated high densities of 'newly settling' G. morhua (i.e. $>0.5 \mathrm{~m}^{-2}$ ) at many of their sites. Only in

Table 2. Probability values from randomized intervention analysis (RIA) of Gadus morhua and Gadus ogac from 2 experimental removal sites (DS and BC) and 5 natural eelgrass reference sites (BB, HC, MC, MI, SB and WR). (-) or (+) indicates a negative or positive effect from the removal $\left({ }^{*} p<0.05,{ }^{* *} p<0.01\right)$

\begin{tabular}{|c|c|c|c|c|c|c|c|}
\hline Year & Site & $\mathrm{MC}$ & MI & SB & WR & $\mathrm{BB}$ & $\mathrm{HC}$ \\
\hline \multicolumn{8}{|c|}{ G. morhua } \\
\hline \multirow[t]{2}{*}{1999} & DS & (-) 0.146 & $(-) 0.153$ & $(-) 0.029^{*}$ & (-) 0.217 & (-) $0.025^{*}$ & $(-) 0.278$ \\
\hline & $\mathrm{BC}$ & (-) 0.158 & (-) $0.027^{*}$ & (-) $0.017^{*}$ & (-) 0.308 & (-) $0.001^{*}$ & (-) $0.026^{*}$ \\
\hline \multirow[t]{2}{*}{2000} & DS & (-) 0.484 & $(-) 0.022^{*}$ & $(-) 0.153$ & (+) 0.079 & (-) 0.650 & $(-) 0.252$ \\
\hline & $\mathrm{BC}$ & 0.220 & (-) 0.060 & (-) $0.035^{*}$ & (-) 0.794 & (-) 0.373 & 0.058 \\
\hline \multirow[t]{2}{*}{2001} & DS & $(-) 0.277$ & $(-) 0.667$ & $(-) 0.031^{*}$ & $(-) 0.560$ & (-) 0.462 & (-) 0.964 \\
\hline & $\mathrm{BC}$ & (-) 0.175 & (-) 0.852 & (-) 0.055 & (-) 0.296 & 0.099 & (-) 0.304 \\
\hline \multicolumn{8}{|c|}{ G. ogac } \\
\hline \multirow[t]{2}{*}{1999} & DS & (-) $0.024^{*}$ & (-) 0.212 & $(-) 0.012^{*}$ & (-) 0.234 & $(-) 0.033^{*}$ & (-) $0.010^{*}$ \\
\hline & $\mathrm{BC}$ & (-) $0.032^{*}$ & (-) $0.032^{*}$ & (-) $0.005^{*}$ & (-) 0.056 & (-) $0.001^{*}$ & (-) $0.033^{*}$ \\
\hline \multirow[t]{2}{*}{2000} & DS & (-) $0.022^{*}$ & (-) 0.158 & (-) $0.002^{*}$ & (-) 0.655 & (-) 0.425 & (-) $0.005^{*}$ \\
\hline & $\mathrm{BC}$ & (-) $0.036^{*}$ & (-) 0.115 & (-) $0.015^{*}$ & (-) 0.681 & (-) 0.110 & (-) $0.002^{*}$ \\
\hline \multirow[t]{2}{*}{2001} & DS & (-) 0.186 & (-) 0.900 & (-) 0.289 & $(-) 0.662$ & (-) 0.777 & $(-) 0.675$ \\
\hline & $\mathrm{BC}$ & 0.293 & (-) 0.424 & (-) 0.473 & (-) 0.741 & (-) 0.4116 & (-) 0.796 \\
\hline
\end{tabular}




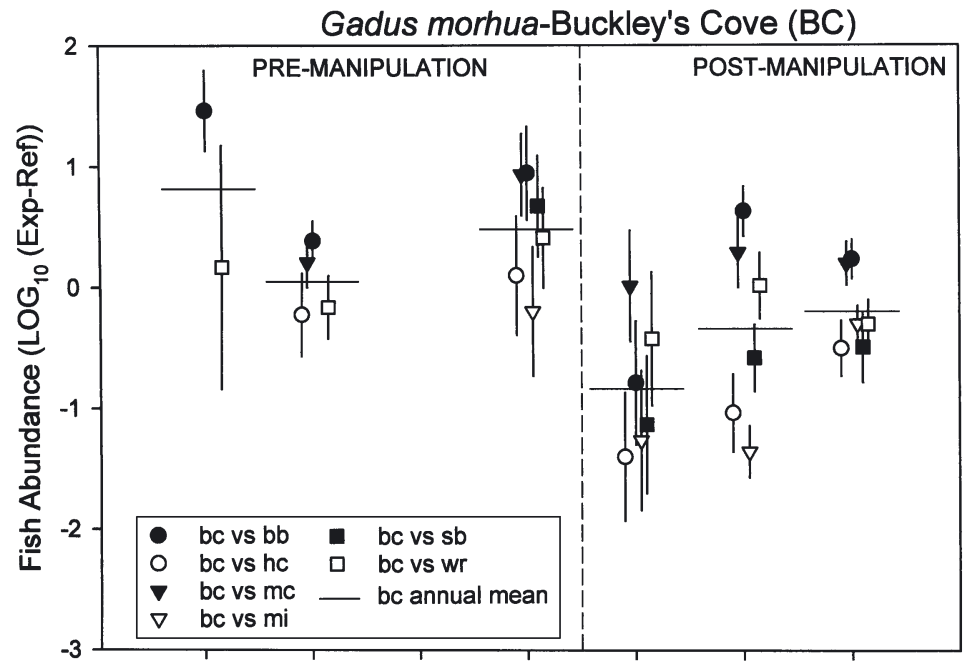

Gadus morhua-Dockside (DS)

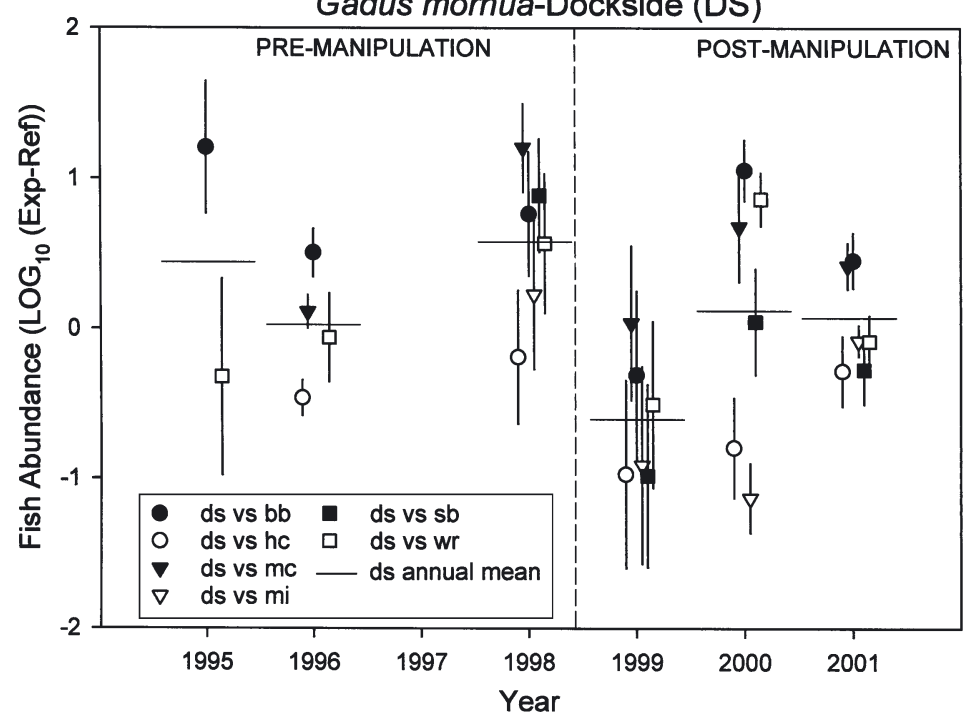

Fig. 7. Gadus morhua. Relative differences of juvenile abundance at experimental removal sites (BC and DS) and natural eelgrass reference sites (BB, HC, MC, MI, SB and WR) during pre- and posthabitat manipulation years. Values represent annual mean biweekly seine catches $(n=14-20) \pm$ SE. Points at each year are staggered ( $0.05 \mathrm{yr})$ for visual purposes

1999 were comparable densities of G. morhua $\left(0.3 \mathrm{~m}^{-2}\right)$ observed in our study. Although comparing densities between studies can be problematic, it is possible that settlement patterns in cod were density dependent. That is, in high abundance years, apparent habitat quality may have decreased through saturation effects (e.g. competition for space, prey, or resources), leading to settlement in suboptimal habitats (i.e. ideal free distribution; MacCall 1990, Kramer et al. 1997). The proximal cause of the disappearance of pre-settling fish from unstructured and removal sites in our study is unknown. However, in a recent study (Laurel et al. in press), we have demonstrated that juvenile cod exhibit increased aggregation behaviour and increased ten- dency to move under conditions of high density when they occupy unstructured habitat, compared to low density, when they did not occupy such habitat. Such behaviour may be a means of compensating for increased predator risk associated with life in unstructured habitats.

An alternative explanation is that settling cod $(<60 \mathrm{~mm})$ initially settled in natural eelgrass sites and shortly afterwards moved to artificial eelgrass sites. However, we suggest that this was unlikely for a number of reasons. First, at our sites, a migration of $>1 \mathrm{~km}$ across deep or unvegetated habitats would be required to relocate to artificial eelgrass sites from natural eelgrass sites. Such a migration would be improbable because risk of predation in juvenile cod increases with water depth (Linehan et al. 2001) and with declining structural complexity (Gotceitas et al. 1997, Laurel et al. 2003). In addition, the susceptibility of juvenile fish to predators is known to be size-dependent (Sogard 1997). Therefore, the risk of movement among safe habitats at small body sizes would likely be prohibitive. Finally, a recent study analyzing patchiness of demersal Gadus morhua within nearshore areas suggests that movement of small pre-settling cod ( 25 to $40 \mathrm{~mm}$ ) is less than that in larger, post-settled fish (Methven et al. 2003). Therefore, in our study, the distribution of small cod $(<60 \mathrm{~mm} \mathrm{SL})$ was likely the result of settlement from the pelagial rather than movements between demersal habitats.

Substantial movement more likely occurred in larger, post-settled juvenile cod. High within-site variation suggests that post-settled cod were not restricted to the area in which they settled. In contrast, Tupper \& Boutilier (1995a,b) have argued that juvenile cod are strongly site-attached and shifts in the observed abundance of settled fish is exclusively due to mortality. In these 2 studies, juvenile Gadus morhua (60 to $100 \mathrm{~mm} \mathrm{SL}$ ) were observed defending small territories and having limited, size-dependent home ranges $\left(<100 \mathrm{~m}^{2}\right)$ for 2 to 3 mo following settlement. Our survey methods encompassed these reported home ranges, yet snorkel observations and seine catches were highly variable between sampling periods. We do not attribute observed variation to mortality alone, since density of post-settled individuals often increased within a site through the season. Therefore, it would appear that both cod species were mobile at scales greater than ca. $1000 \mathrm{~m}^{2}$.

Both cod species altered their distribution following the habitat manipulation, but their habitat use patterns were not identical. Gadus ogac abundance decreased in more removed-eelgrass-control comparisons than G. morhua, suggesting that G. ogac is more sensitive to 

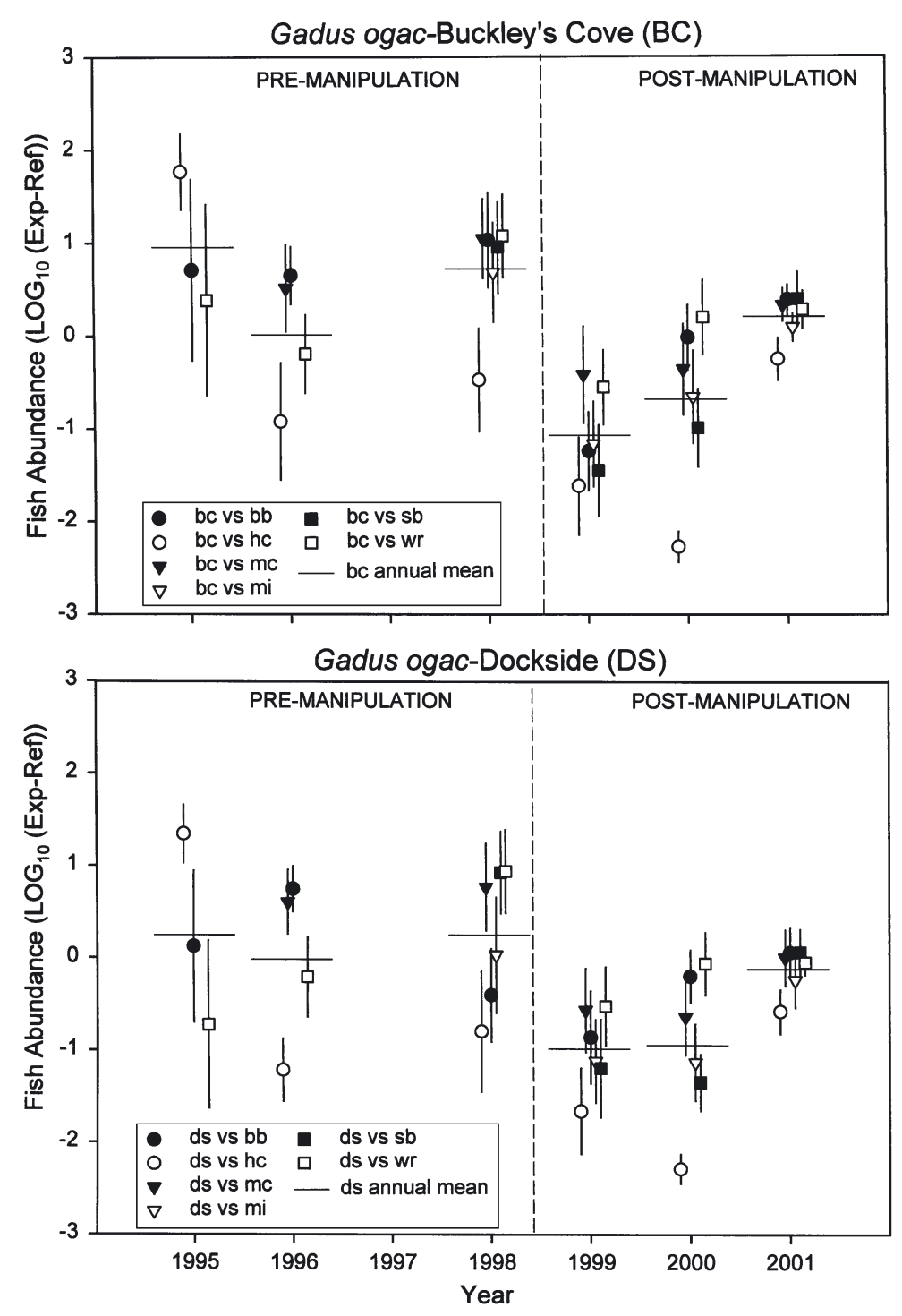

Fig. 8. Gadus ogac. Relative differences of juvenile abundance at experimental removal sites (BC and $\mathrm{DS}$ ) and natural eelgrass reference sites (BB, HC, MC, MI, SB and WR) during pre- and posthabitat manipulation years. Values represent annual mean biweekly seine catches $(n=14-20) \pm$ SE. Points at each year are staggered $(0.05 \mathrm{yr})$ for visual purposes

alterations in habitat complexity. Conversely, despite an overall preference for eelgrass, G. morhua was periodically caught over sand and removal sites, suggesting that habitat use in this species is more flexible at early life stages. Such differences may reflect differences in predation risk outside eelgrass habitat between the 2 species. Alternatively, these differences may reflect different spawning characteristics between the 2 species. G. ogac spawn demersal eggs (Scott \& Scott 1988) in close proximity to nursery areas, whereas G. morhua spawn pelagic eggs, often further offshore (Templeman 1979). Larvae from demersally spawned eggs are more likely to be retained in the area spawned relative to pelagic eggs (Bradbury et al. 2003). It is therefore possible that $G$. morhua evolved a greater tolerance for the use of alternative habitats, such as gravel-cobble (Lough et al. 1989) and rocky reefs (Tupper \& Boutilier 1995a). However, such explanations are tenuous without data on spatial and temporal distributions of eggs, larvae and pelagic juveniles of each species in our study area.

Our analysis measured a relative effect on fish abundance rather than a shift in absolute abundance. Largely, this was done to control for individual site differences (e.g. eelgrass biomass, patchiness, planktonic supply) that could contribute to differential abundance of cod within a habitat treatment. In addition, the artificial eelgrass may not completely mimic natural eelgrass (e.g. additional structure from wire base, lack of natural die-off). However, the logistical constraints of carrying out a large-scale habitat manipulation did not permit us to manipulate habitat of an area equivalent to natural eelgrass control sites. Therefore, absolute comparisons would be inappropriate regardless of possible inherent site differences. Therefore, the high abundance of juvenile cod, namely Gadus morhua, at removal sites was not unexpected; $35 \%$ of each removal site still contained undisturbed eelgrass, although this was only in the shallow intertidal zone where few juvenile fish are found regardless (Jenkins et al. 1997b), including Gadus spp. (M. Norris unpubl.). Another source of juvenile cod in the removal sites were the edges along the subtidal boundary of the removal. We observed schools of juvenile cod along the deeper edge of our removal sites where the manipulated area adjoined undisturbed eelgrass, but we rarely observed cod over the interior of the removal. Edge areas in eelgrass are known to be profitable foraging areas for fish (Graham et al. 1998), and it is possible that edgeassociated fish contributed substantially to our seine catches. In addition, removal sites may have had higher prey levels than sand sites. Although the response of macroinvertebrates to alterations in seagrass is species- and site-specific (e.g. Edgar \& Robertson 1992, Connolly \& Butler 1996, Lee et al. 2001), Connolly (1994) found higher overall invertebrate abundance in small removal areas $\left(25 \mathrm{~m}^{2}\right)$ compared to naturally unvegetated areas. In our study, we removed the canopy of eelgrass and left the rhizomes intact in the benthos. Potentially, our procedure left a rich benthic invertebrate community relative to naturally unvegetated sites. 
In a few instances, highest numbers of juvenile cod were caught in artificial eelgrass sites. This was interesting considering that the eelgrass coverage at artificial sites was substantially less than natural sites. The visual transect data, which controls for habitat area, also confirmed that overall cod abundance was higher in our artificial eelgrass. These results may demonstrate an 'oasis effect', since artificial eelgrass sites were further removed from natural eelgrass patches than natural eelgrass sites. Assuming fish seek the most proximate refuge, patches of suitable habitat may be colonized at high rates when surrounded by large areas of unsuitable habitat (Virnstein \& Curran 1986). Other studies have shown that higher densities of fish are found in isolated patches of eelgrass (Sogard 1989) and reef habitat (Schroeder 1987) when compared to continuous sections of the same type of habitat. Similar findings have also been reported for cod. Eelgrass sites with slight fragmentation supported higher densities of Age-0 juvenile cod than eelgrass meadows of equivalent area (Wells 2002). Our results were consistent with these findings.

Appreciable regrowth of eelgrass at the removal sites occurred $2 \mathrm{yr}$ following its initial removal. This regrowth was reflected in the number of significant RIA removal-control site comparisons. In the first year of removal (1999), nearly $50 \%$ of the RIA comparisons indicated a significantly lower juvenile cod abundance in removal sites compared to years prior to the removal. By 2001, differences between removal and vegetated sites were no longer significant. Eelgrass reproduces both sexually and asexually (Orth et al. 1994). The close proximity of undisturbed eelgrass to the removal areas also likely facilitated the quick recovery. A larger, more geographically isolated removal location or a complete removal of canopy, including rhizomes (which we left largely intact) may have had longer-term effects on juvenile cod distribution.

\section{CONCLUSIONS}

Both Gadus ogac and G. morhua abundance increased at sites enhanced with artificial eelgrass and decreased at sites where eelgrass was removed, relative to years before we manipulated habitat. Therefore, we reject the hypothesis that broad-scale processes (e.g. larval supply and oceanographic hydrodynamics) were responsible for the differential use of vegetated and unvegetated habitats. The presence of settling cod over sites with artificial eelgrass in years of high and low abundance suggests that these species are capable of selecting habitat while still in the pelagial.
Both species exhibited an overall preference for eelgrass habitat. However, high within-site variability of both species indicated that both species are not strongly site attached. High catch variability was especially evident in Gadus morhua. Significant RIA comparisons were fewer in G. morhua relative to G. ogac, suggesting that $G$. morhua was less site attached or less dependent on habitat complexity than its sibling species. These data contradict Tupper \& Boutlier's $(1995 \mathrm{a}, \mathrm{b})$ accounts of cod (1) settling indiscriminately across a range of habitats and (2) having high site fidelity following settlement.

Acknowledgements. This project was supported by NSERC Strategic Projects Grant no. 20234. We would like to thank Parks Canada (Terra Nova National Park) for providing accommodation and access to facilities and the Department of Fisheries and Oceans for boats and motors. Finally, we are indebted to C. Anderson, J. Anderson, L. Copeman, D. Cote, P. Frampton, D. Gibson, A. Gorman, J. Hancock, L. Hancock, D. Ings, T. Lander, M. O, A. Ogilvie, P. Sargent, K. Smedbol and N. Wells for countless hours constructing artificial eelgrass and in the field completion of field surveys.

\section{LITERATURE CITED}

Bell JD, Pollard DA (1989) Ecology of fish assemblages and fisheries associated with seagrasses. In: Larkum AWD, McCoomb AJ, Shepherd SA (eds) Biology of seagrasses: a treatise on the biology of seagrasses with special reference to the Australian region. Elsevier, Amsterdam, p 565-609

Bell JD, Steffe AS, Westoby M (1988) Location of seagrass beds in estuaries: effects on associated fish and decapods. J Exp Mar Biol Ecol 117:93-114

Bell JD, Westoby M (1986) Variation in seagrass height and density over a wide spatial scale: effects on common fish and decapods. J Exp Mar Biol Ecol 104:275-295

Bradbury IR, Snelgrove PVR, Pepin P (2003) Passive and active behavioural contributions to patchiness and spatial pattern during the early life history of marine fishes. Mar Ecol Prog Ser 257:233-245

Carpenter SR, Frost TM, Heisey D, Kratz TK (1989) Randomized intervention analysis and the interpretation of wholeecosystem experiments. Ecology 70:1142-1152

Caselle JE, Warner RR (1996) Variability in recruitment of coral reef fishes: the importance of habitat at two spatial scales. Ecology 77:2488-2504

Connolly RM (1994) Removal of seagrass canopy: effects on small fish and their prey. J Exp Mar Biol Ecol 184:99-110

Connolly RM, Butler AJ (1996) The effects of altering seagrass canopy height on small, motile invertebrates of shallow Mediterranean embayments. PSZN I:Mar Ecol 17:637-652

Edgar GJ, Robertson AI (1992) The influence of seagrass structure on the distribution and abundance of mobile epifauna: pattern and process in a Western Australian Amphibolis bed. J Exp Mar Biol Ecol 160:13-31

Edgar GJ, Shaw C (1995a) The production and trophic ecology of shallow-water fish assemblages in southern Australia. 3. General relationships between sediments, seagrasses, invertebrates and fishes. J Exp Mar Biol Ecol 194:107-131 
Edgar GJ, Shaw C (1995b) The production and trophic ecology of shallow-water fish assemblages in southern Australia I. Species richness, size-structure and production of fishes in Western Port, Victoria. J Exp Mar Biol Ecol 194: $53-81$

Fahay MP (1983) Guide to the early stages of marine fishes occurring in the western North Atlantic Ocean, Cape Hatteras to the southern Scotian Shelf. J Northwest Atl Fish Sci 4:1-423

Gotceitas V, Fraser S, Brown JA (1995) Habitat use by juvenile Atlantic cod (Gadus morhua) in the presence of an actively foraging and non-foraging predator. Mar Biol 123: 421-430

Gotceitas V, Fraser S, Brown JA (1997) Use of eelgrass beds (Zostera marina) by juvenile Atlantic cod (Gadus morhua) Can J Fish Aquat Sci 54:1306-1319

Graham S, Davis J, Deegan L, Cebrian J, Hughes J, Hauxwell $\mathrm{J}$ (1998) Effect of eelgrass (Zostera marina) density on the feeding efficiency of mummichog (Fundulus heteroclitus). Biol Bull 195:241-243

Grant SM, Brown JA (1998a) Nearshore settlement and localized populations of age 0 Atlantic cod (Gadus morhua) in shallow coastal waters of Newfoundland. Can J Fish Aquat Sci 55:1317-1327

Grant SM, Brown JA (1998b) Diel foraging cycles and interactions among juvenile Atlantic cod (Gadus morhua) at a nearshore site in Newfoundland. Can J Fish Aquat Sci 55: 1307-1316

Hindell JS, Jenkins GP, Keough MJ (2000) Evaluating the impact of predation by fish on the assemblage structure of fishes associated with seagrass (Heterozostera tasmanica) (Martens ex Ascherson) den Hartog, and unvegetated sand habitats. J Exp Mar Biol Ecol 255:153-174

Holbrook SJ, Schmitt RJ (1988) The combined effects of predation risk and food reward on patch selection. Ecology 69:125-134

Horinouchi M, Sano M (1999) Effects of changes in seagrass shoot density and leaf height on abundances and distribution patterns of juveniles of three gobiid fishes in a Zostera marina bed. Mar Ecol Prog Ser 183:87-94

Irlandi EA (1997) Seagrass patch size and survivorship of an infaunal bivalve. Oikos 78:511-518

Jenkins GP, Wheatley MJ, Poore AJB (1996) Spatial variation in recruitment, growth, and feeding of postsettlement King George whiting, Sillaginodes punctata, associated with seagrass beds of Port Phillip Bay, Australia Can J Fish Aquat Sci 53:350-359

Jenkins GP, Black KP, Wheatley MJ, Hatton DN (1997a) Temporal and spatial variability in recruitment of a temperate, seagrass-associated fish is largely determined by physical processes in the pre-and post-settlement phases. Mar Ecol Prog Ser 148:23-35

Jenkins GP, May HMA, Wheatley MJ, Holloway MG (1997b) Comparison of fish assemblages associated with seagrass and adjacent unvegetated habitats of Port Phillip Bay and Corner Inlet, Victoria, Australia, with emphasis on commercial species. Estuar Coast Shelf Sci 44:569-588

Jenkins GP, Keogh MJ, Hamer PA (1998) The contributions of habitat structure and larval supply to broad-scale recruitment variability in temperate zone, seagrass-associated fish. J Exp Mar Biol Ecol 226:259-278

Jenkins GI, Walker Smith GI, Hamer PI (2002) Elements of habitat complexity that influence harpacticoid copepods associated with seagrass beds in a temperate bay. Oecologia 131:598-605

Kramer DL, Rangley RW. Chapman LJ (1997) Habitat selection: patterns of spatial distribution from behavioural decisions. In: Godin JGJ (ed) Behavioural ecology of teleost fishes. Oxford University Press, Oxford, p 37-80

Laurel BJ, Gregory RS, Brown JA (2003) Predator distribution and habitat patch area determine predation rates on Age-0 juvenile cod Gadus spp. Mar Ecol Prog Ser 251: 245-254

Laurel BJ, Gregory RS, Brown JA, Hancock J, Schneider D (in press) Behavioural consequences of density-dependent habitat use in juvenile cod Gadus morhua: role of movement and aggregation. Mar Ecol Prog Ser

Lee SY, Fong CW, Wu RSS (2001) The effects of seagrass (Zostera japonica) canopy structure on associated fauna: a study using artificial seagrass units and sampling of natural beds. J Exp Mar Biol Ecol 259:23-50

Levin PS (1991) Effects of microhabitat on recruitment variation in a Gulf of Maine reef fish. Mar Ecol Prog Ser 75:183-189

Linehan JE, Gregory RS, Schneider DC (2001) Predation risk of age 0 cod (Gadus morhua) relative to depth and substrate in coastal waters. J Exp Mar Biol Ecol 263:25-44

Lomond TM, Schneider DC, Methven DA (1998) Transition from pelagic to benthic prey for age group 0-1 Atlantic cod (Gadus morhua). Fish Bull 96:908-911

Lough RG, Valentine PC, Potter DC, Auditore PJ, Bolz GR, Neilson JD, Perry RI (1989) Ecology and distribution of juvenile cod and haddock in relation to sediment type and bottom currents on eastern Georges Bank. Mar Ecol Prog Ser 56:1-12

MacCall AD (1990) Dynamic geography of marine fish populations. University of Washington Press, Seattle, WA

Marliave JB (1977) Substrate preferences of settling larvae of marine fishes reared in the laboratory. J Exp Mar Biol Ecol $27: 47-60$

Mattila J, Chaplin G, Eilers MR, Heck KL Jr, O'Neil JP, Valentine JF (1999) Spatial and diurnal distribution of invertebrate and fish fauna of a Zostera marina bed and nearby unvegetated sediments in Damariscotta River, Maine (USA). J Sea Res 41:321-332

Methven DA, Bajdik C (1994) Temporal variation in size and abundance of juvenile Atlantic cod (Gadus morhua) at an inshore site off eastern Newfoundland. Can J Fish Aquat Sci 51:78-90

Methven DA, McGowan C (1998) Distinguishing small juvenile Atlantic cod (Gadus morhua) from Greenland cod (Gadus ogac) by comparing meristic characters and discriminant function analyses of morphometric data. Can J Zool 76:1054-1062

Methven DA, Schneider DS, Rose GA (2003) Spatial patterns and patchiness during ontogeny: post-settled Gadus morhua from coastal Newfoundland. ICES J Mar Sci 60:38-51

Mikhail MY, Welch HE (1989) Biology of Greenland cod, Gadus ogac, at Saqvaqjuac, northwest coast of Hudson Bay. Environ Biol Fish 26:49-62

Morin B, Hudon C, Whoriskey F (1991) Seasonal distribution, abundance, and life-history traits of Greenland cod, Gadus ogac, at Wemindji, eastern James Bay. Can J Zool 69:3061-3070

Orth RJ, Heck KL Jr, van Montfrans J (1984) Faunal communities in seagrass beds: a review of the influence of plant structure and prey characteristics on predator-prey relationships. Estuaries 7:339-350

Parker JD, Duffy JE, Orth RJ (2001) Plant species diversity and composition: experimental effects on marine epifaunal assemblages. Mar Ecol Prog Ser 224:55-67

Sale PF, Douglas WA, Doherty PJ (1984) Choice of microhabitats by coral reef fishes at settlement. Coral Reefs 3: 91-99 
Schmitt RJ, Holbrook SJ (1985) Patch selection by juvenile black serfperch (Embiotocidae) under variable risk: interactive influences or food quality and structural complexity. J Exp Mar Biol Ecol 85:269-285

Schmitten RA (1996) National Marine Fisheries Service: seeking partners for its National Habitat Plan and identifying essential fish habitats. Fisheries 21:4

Schroeder RE (1987) Effects of patch reef size and isolation on coral reef fish recruitment. Bull Mar Sci 41:289-295

Scott WB, Scott MG (1988) Atlantic fishes of Canada. Can Bull Fish Aquat Sci 219

Smedbol RK, Schneider DC, Wroblewski JS, Methven DA (1998) Outcome of an inshore spawning event by northern Atlantic cod (Gadus morhua) at a low stock level. Can J Fish Aquat Sci 55:2283-2291

Sogard SM (1989) Colonization of artificial seagrass by fishes and decapod crustaceans: importance of proximity to natural eelgrass. J Exp Mar Biol Ecol 133:15-37

Sweatman H (1985) The influence of adults on some coral reef

Editorial responsibility: Kenneth Heck (Contributing Editor), Dauphin Island, Alabama, USA fishes on larval recruitment. Ecol Monogr 55:469-485

Templeman W (1966) Marine resources of Newfoundland bulletin. Fish Res Board Can Bull 154

Templeman W (1979) Migration and intermingling of stocks of Atlantic cod, Gadus morhua, of the Newfoundland and adjacent areas from tagging in 1962-66. Res Bull ICNAF 14:5-50

Tupper M, Boutilier RG (1995a) Effects of habitat on settlement, growth, and post-settlement survival of Atlantic cod (Gadus morhua). Can J Fish Aquat Sci 52:1834-1841

Tupper M, Boutilier RG (1995b) Size and priority at settlement determine growth and competitive success of juvenile Atlantic cod. Mar. Ecol. Prog. Ser. 118:295-300

Virnstein RW, Curran MC (1986) Colonization of artificial seagrass versus time and distance from source. Mar Ecol Prog Ser 29:279-288

Wells N (2002) A fractal analysis of nearshore eelgrass complexity in Newfoundland. MSc thesis, Memorial University of Newfoundland, St. John's

Submitted: July 10, 2002; Accepted: July 1, 2003

Proofs received from author(s): October 15, 2003 